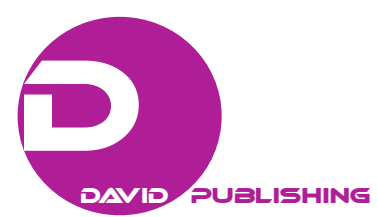

\title{
Dry Stone Masonry Ductility During an Earthquake
}

\author{
António Morais \\ University of Lisbon, Lisbon, Portugal
}

\begin{abstract}
Stone structures with dry joints, that is, without mortar, have shown a surprising behavior when earthquakes occur. An example of this behavior is the perennially of the so-called Inca wall in Peru, which despite having suffered several earthquakes over time has remained stable without collapsing. This article presents the research carried out on stone masonry walls with dry joint, without mortar, subject to a seismic action. In order to understand the behavior of the masonry without mortar, it designs a Grid model of Finite Elements. From the results, it is concluded that these walls with a certain thickness have ductility that allows them to withstand high displacement and rotation values, thus accommodating the movement of the earth subject to an earthquake. The individual stone blocks move relative to each other through rotations and displacements, which are processed in the free joints of any mortar. The joints work as energy sinks. The free movements in the joints dissipate the energy transmitted by the earthquake, not causing in this way the rupture of the stone blocks. The goal of this article is to understand the importance of lack of mortar in the seismic behavior of the mansonry.
\end{abstract}

Keywords: dry masonry, masonry structural performance, numerical models, resistant parameters, earthquake behavior, seismic resistance

\section{Introduction}

This paper presents the conclusions of a research carried out on the masonry wall without filling in their joints. The investigation tries to understand why stone masonry buildings with non-mortar in the joints present a relative good capacity to support the action of earthquakes, as is the case of the Inca wall (Figure 1). In order to achieve this goal we used a finite element program designed for this purpose, which has the particularity to manage the dry joint, in other words, joints that are not filled by mortar. In this article, the author presents the results.

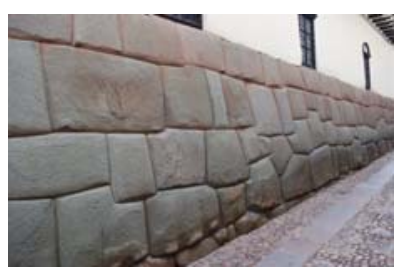

Figure 1. Inca wall.

Acknowledgment: This research is a result of a research line entitled Seismic Rehabilitation of Old Buildings supported by the Centre for Investigation of Architecture, Urbanism and Design, CIAUD, of the Faculty of Architecture of the University of Lisbon, which is funded and supported by the FCT, the Foundation for Science and Technology, the Portuguese national funding agency for science, research and technology.

António Morais, Ph.D., associate teacher, Structural Engineering, Faculty of Architecture, University of Lisbon, Lisbon, Portugal.

Correspondence concerning this article should be addressed to António Morais, Rua Sá Nogueira, Pólo Universitário, Alto da Ajuda, 1349-063 Lisboa, Portugal. 


\section{Design Model}

The elaborated mechanical model allows us to study the seismic response of masonry structures, for several scenarios of possible actions.

Figures 2 and 3 show the geometries of the masonry studied, all with unfilled joints.

Two of them are composed of double vertical columns, differentiated by the interlocking of the joints, and the other simulates a vertical column of masonry.

For the blocks' material were adopted following values, considered characteristic of their mechanical properties.

\section{Tests Performed and Analysis of the Results Obtained}

- Modulus of elasticity $500 \mathrm{Mpa}$

- Poisson coefficient 0.2;

- Angle of friction (joint) 30;

- Cohesion (joint) 0.05 Mpa;

- Tensile strength (joint) 0 ;

- Normal rigidity (joint) $100 \mathrm{Mpa}$

- Transverse stiffness (joint) 100 Mpa;

- Density 30 Mpa;

- Compressive strength 100 Mpa.

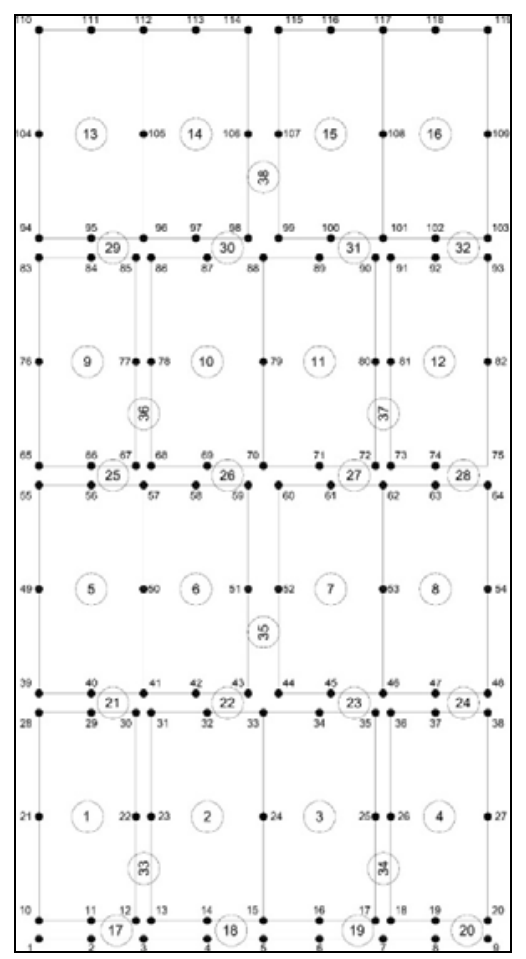

Figure 2. Finite elements grid.

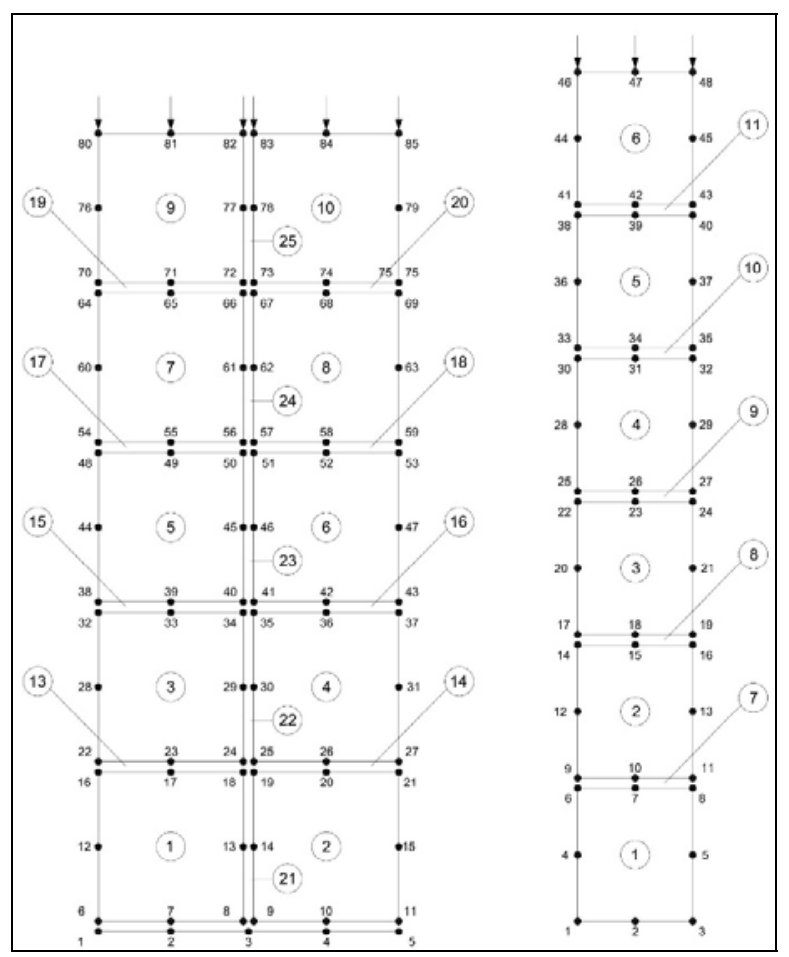

Figure 3. Finite elements grid.

For simulation of the seismic action occurring on the three masonry structures, two sets of values were considered (Morais, 2016). In the case of the vertical column, it was adopted as a reference the seismic wave velocity was recorded in 1972 in El Centro, California. 
For the walls with two vertical columns was assumed a set of values for the seismic velocities, with triangular shape in time, but due to high values, the probability of occurrence in practical terms is null (Paul, 1961).

As expected, seismic action takes some time to reach the top of the structures, only acting point 85 of the masonry structure with vertical columns aligned in step 20, therefore after the quake ends, at step 19 . While for the same structure, point 27 has horizontal displacement on step 10, although this is in the opposite direction to point 85.

From the analysis of the progress of the tensions along the calculation, it is verified that this structure initiates the rupture process in the step 15, where the finite element 21 has total rupture by cut.

However, no element has rupture by tension stress, so slides are being processed at that moment but there are still no separations between blocks, which are only processed at step 30, after the earthquake has ended.

The total rupture with separation between blocks starts at step 64 in the finite element 24. In the end of the calculation, which is the important conclusion, it is verified that the two vertical columns of blocks are separated because tension stress occurred in the joint and the block 9 shifted by translation and turned to the left, because of the rupture by cutting of its base in the joint number 19, originated by the displacement of the masonry wall in its upper par.

In order to evaluate the possible best behavior, produced by the seismic actions in the masonry walls, in which vertical joints are not continuous, a masonry wall is studied with the same dimensions and geometry, and for the same seismic action, a masonry wall in which the vertical joints are not continuous.

From the results, it is observed that with this different arrangement, of the blocks one on the other, it occurs a significant increase in the seismic resistance of the masonry wall, which for the same seismic action does not collapse, it remaining stand up, occurring only slides per cut of very small value, negligible in practical terms negligible, at the level of the joints located inferiorly, while in the previous structure the rupture started at step 15, now only slicing per cut occurs at step 20 and the total rupture by tension stress never processes.

On the other hand, it can be seen that in this situation the sliding by cutting occurs in the horizontal joints located inferiorly, near to the supports, whereas in the previous case they occurred in the upper vertical joints. They are the elements $17,18,19,20,22,33$, and 34 that are ruptured by cutting, which are located in the lower part of the wall of masonry.

In physical terms, with non-continuous and cross-linked vertical joints, the blocks suffer greater restrictions in their potential translation movements, but continue to perform oscillation movements, which act as a dissipation damper for the energy introduced by the earthquake.

In the case of the individual column subject to the record of the seismic action occurring in El Centro, California, the rupture occurs by collapse of the uppermost block after rupture by cutting the underlying joint, which rotates on the left side of the column.

Figures 2 and 3 show the calculated register for the horizontal displacement of the upper right corner of the column, that is, the point 48 of the finite element mesh.

The analysis of this register allows us to conclude that the stone block oscillates in cycles over time, increasing and decreasing the value of the horizontal displacement. The maximum displacement calculated with the program has reached a maximum of $37 \mathrm{~cm}$. 
This is a very high value, which justifies the apparent good behavior of dry-jointed masonry, such as the Inca wall (Rocha, 1971).

But from the analysis of the record of Figure 4 we realize that the horizontal displacement, at that point 48 , does not continuously increase its value, since it oscillates, increasing and decreasing.

This behavioral phenomenology means that the block is dissipating energy, because in certain cycles, the displacement decreases.

The author concludes that stone masonry with dry joint has the capacity to move in a pronounced way, that is, it has a type of ductility that allows it to withstand high displacements $(37 \mathrm{~cm})$. This behavior enables it to withstand seismic movements.

The elaborated mechanical model allows studying the seismic response of masonry structures, for several scenarios of possible actions. Considering the results obtained in the characterization of the seismic behavior of these, we can equate different solutions of reinforcement of the seismic resistance simulating with this model the dynamic responses of the constructions.

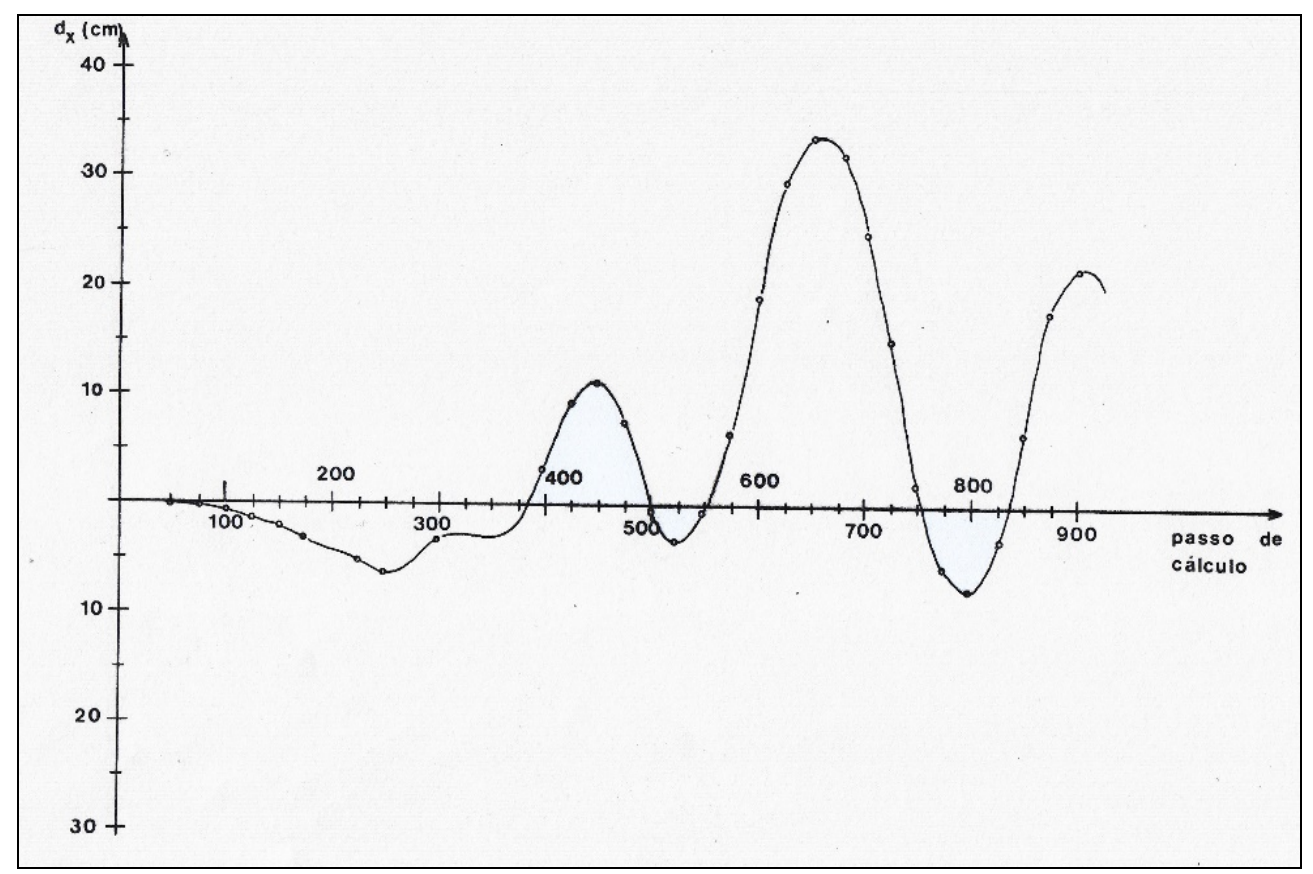

Figure 4. Horizontal displace in the point 48.

\section{Conclusions}

The research carried out allows us to conclude the following about the behavior of dry stone masonry:

- Stone masonry with dry joints, such as the Inca wall, has a positive oscillatory behavior that allows it to function as an energy sink when an earthquake occurs;

- The dry joint allows you to accommodate displacements of appreciable value, providing ductility for this particular type of masonry;

- The drywall masonry and the Inca wall have an appreciable resistant capacity when an earthquake occurs. Parametric studies which adopt progressively lower values for the parameters of resistant masonry joints led to a gradual increase in efforts in frame parts. 


\section{References}

Morais, A. J. (2016). Modelo de Cálculo de Alvenarias Estruturais Pré-esforçadas pelo Método dos Elementos Finitos. Edição do Autor. Lisboa.

Morais, A. J. (2016). Influences of the frames' fill masonry in the buildings structuralb. IX International Conference on Latest Trends in Engineering and Technology (ICLTET'2016).

Paul, G. (1961). Modification of Coulomb-Mohr theory of fracture. Journal of Applied Mechanics.

Rocha, M. (1971). Curso de Mecânica das Rochas. Lisboa: LNEC. 